\title{
GUEST EDITORS’ NOTE
}

Issues 56/4 and 57/1 of Acta Linguistica Hungarica are devoted to contributions to the description of Hungarian from a functional cognitive perspective. Both issues have been planned, edited and written by members of the Functional cognitive linguistics workshop at the Institute of Hungarian and Finno-Ugric Linguistics, Eötvös Loránd University, Budapest. For some background information about the group and its general objectives, see the Guest editors' note of the $56 / 4$ issue.

The present issue of Acta Linguistica Hungarica contains seven papers written by group members, bringing the overall number to a total of eleven papers. What follows is a brief description of each new contribution.

'On the status of discourse markers' by Csilla Ilona Dér. Discourse markers appear to withstand approaches trying to account for them in terms of formal properties, but a function-based description has its own problems, too. The purpose of Dér's paper is to review the major theoretical problems related to discourse markers, including difficulties in referring to them and in listing their definitive features. Also, an effort is made to highlight crucial functional factors in the delimitation of the group and to discuss the status of multi-word discourse markers.

'Variability in Hungarian address forms' by Ágnes Domonkosi explores variability within the Hungarian system of address, building on the results of an empirical investigation. According to the findings, the Hungarian system of address cannot be described simply as a binary system involving the choice between $\mathrm{T}$ and $\mathrm{V}$; rather, it contains a combination of address forms of various social indexical values. In addition to providing an overview of the possible variants, the paper also comments on the role of switching between different variants within the same relationship.

'Illocutionary force, salience and attention management - a social cognitive pragmatic perspective' by Ágnes Hámori discusses salience and foregrounding in speech acts from a social cognitive pragmatic perspective, interpreting the salience of illocutionary force in terms of ease of mental access and processing costs. The author cites examples to show that the illocutionary force of utterances may be salient to varying degrees, and makes an attempt to characterize the most important linguistic possibilities of foregrounding in speech acts. Finally, a short analysis of a political debate illustrates how the foregrounding of certain illocutionary forces or leaving them in the background may become part of the speaker's discourse strategy.

Nóra Kugler's paper, 'Modal adverbs in Hungarian (The case of talán 'perhaps')' provides an overview of inferential-epistemic modal adverbs in Hungarian, and investigates the semantic structure of talán 'perhaps' in detail, with 
special regard to the paths of leaving the modal domain. The description relies on corpus-based research.

Krisztina Laczkó's paper 'Space deixis, discourse deixis and anaphora' investigates the functioning of space deixis through demonstrative pronouns, accommodates discourse deixis into this system, and analyzes the role of Hungarian demonstrative pronouns (prototypically containing front vowels in this function) in pointing at elements of a contextually situated and evolving discourse. The paper also attempts to account for (i) the relationship between pronominal discourse deixis and demonstrative pronominal anaphora, and (ii) the role of vowel-quality differences in the use of pronouns. The author concludes that the operations involved in both deixis and anaphora ultimately depend on perspectivization.

Kornélia Papp's study 'What is nagy 'big'?' combines the usage-based method with cognitive-functional analyses in two new areas of research. Firstly, Hungarian has enjoyed comparatively little attention regarding contemporary empirical methods in analytical frameworks. Secondly, adjectives, due to their abstract and 'shared' semantics, are seldom analysed quantitatively. Papp's paper is concerned with adjective-noun readings in context and she reports on a corpus-based study of meaning variation in nagy-noun combinations. Her findings suggest that prototypicality-based frequency estimates are sometimes misleading.

Gábor Tolcsvai Nagy's paper, 'The auxiliary + infinitive construction in Hungarian', gives a descriptive overview of the prototypical Hungarian auxiliary + infinitive construction, discussing it in the framework of functional cognitive grammar worked out by Ronald Langacker and in terms of Bernd Heine's grammaticalization theory for auxiliaries. He suggests that the Hungarian auxiliary serves the function of imposing temporality on a non-temporal infinitive, and also that of the grounding predication, which marks a departure from Langacker's model for English. Also, degrees of subjectification contribute to types of construal, yielding a dimension of variation that cannot be derived from the deontic/epistemic distinction.

In the final stage of preparing their contributions, the authors benefited greatly from the useful comments and insightful suggestions of their reviewers, whose work is hereby gratefully acknowledged. Our panel of reviewers for the present issue includes Dylan Glynn, John Haiman, Andreas H. Jucker, László Komlósi, Edith Moravcsik, Simone Müller, Heiko Narrog, Catrin Norrby, Jan Nuyts, Enikő Németh T., Clarita Paradis, Péter Pelyvás, Katalin Szili and Szilárd Tátrai. Naturally, the authors take full responsibility for any errors or shortcomings that remain.

The contents of both issues have been completed within the scientific project 'Funkcionális kognitív nyelvészeti kutatás' (Functional cognitive linguistics research) supported by grant K 76878 of OTKA (Hungarian Scientific Research Fund).

Gábor Tolcsvai Nagy Mária Ladányi 